William G. Boltz

\title{
Textual Criticism and Early Chinese Manuscripts
}

\begin{abstract}
Because of the differing kinds of writing systems used, differences in the history of printing and different traditions of identifying individual texts with individual authors, the assumptions and methods of textual criticism when approaching early Chinese texts will be different from those aspects of textual criticism as they are conventionally understood in regard to classical western and early Near Eastern texts. In particular the nature of the Chinese writing system, fundamentally logographic (or morphographic), makes the distinction between graphic variation and lexical variation in a given instance considerably less obvious than typically is the case with texts written in alphabets, abugidas or abjads. Beyond this, recognizing authorial identification of a given early text as a proprietary matter is much less a central feature of the history of a given text in China than it is in the western tradition. For these reasons among others, textual criticism as a scholarly approach to early Chinese texts will necessarily take a form markedly different from its practice in the western scholarly tradition.
\end{abstract}

The twentieth-century Oxford scholars L. D. Reynolds and N. G. Wilson, after a two-hundred page survey of the history of classical literature in the west from its origins in antiquity to its mature philological study at the end of the eighteenth century, introduce in the sixth and final chapter of their well-known book Scribes and Scholars, A Guide to the Transmission of Greek and Latin Literature the subject of textual criticism, by saying

The foregoing chapters have attempted to give some idea of the ways in which the Greek and Latin classics were handed down through the Middle Ages to the modern world, and to outline some of the more important historical and cultural phenomena which affected the transmission of these texts. The business of textual criticism is in a sense to reverse this process, to follow back the threads of transmission and try to restore the texts as closely as possible to the form which they originally had. ${ }^{1}$

1 Reynolds and Wilson 1991, 207 (italics added). 
Though they do not give an explicit or precise definition of textual criticism, their description all the same identifies the central focus of textual criticism as a process for, ideally, restoring the original form of transmitted texts from the evidence of their extant descendants. As a practical matter, the goal is to come as close to the original as possible, while recognizing that sometimes the exact wording or form of the original text might not be recoverable.

The subject of textual criticism understood specifically as a means to recover the authentic, original form of early texts emerged from the tradition of European humanist philology of the fifteenth through seventeenth centuries, what Anthony Grafton calls the 'tradition of scholarship' in the 'age of science'. The expressed goal was to identify and eliminate textual errors and corruption so as to restore a literary text to a form as close to its original as possible. E. J. Kenney, writing in the fifteenth edition of the Encyclopaedia Britannica, says '[t]extual criticism is the technique of restoring texts as nearly as possible to their original form'. ${ }^{3}$ The eminent Cambridge Latinist of the early twentiethcentury, A. E. Housman, in a now classic paper put it more forcefully, saying that '[t]extual criticism is a science, and, since it comprises recension and emendation it is also an art. It is the science of discovering error in a text and the art of removing it'. ${ }^{4}$

In all of these descriptions, textual criticism is said explicitly to consist in a concern with errors in texts and the means for correcting them, the goal being to come as close to the original form of the text as possible. While this may be in some sense the primary goal, it is not the only possible goal. Textual critics recognize, among other aspects of the history of a text, the importance of analyzing a text diachronically according to its transmission or reception history, identifying and understanding the impact of change in texts over time. Whether that approach is taken in order to undo the changes, in the hope of restoring the original form, or to examine how the changes came about and what they mean for the interpretation of the text at particular moments in the course of its transmission history, or with still some other goal in mind depends on the preferences of the textual critic and the nature of the study in question. ${ }^{5}$

2 Grafton 1991.

3 Kenney 1974b (online edition).

4 Housman 1922; D. C. Greetham has suggested that '[...] today most practicing textual critics would probably insist that art and science are equally mixed in both parts of Housman's equation'. See Greetham 1994, 346.

5 Walsh 2013. 
The presumption is that any literary text $\mathbf{T}$ starts out life in a form we can call $\boldsymbol{\omega}$, its original form, the form that it had when it was first written, and that this original form suffers changes in the course of its transmission over time. Changes can be of any kind, e.g., additions, losses, alterations, substitutions; of any size or extent, from single letters to whole passages. They can be the consequence of a wide range of misunderstandings, visual, verbal, aural or interpretive; and they can be inadvertent or intentional. The result of any change is a textual variant, that is, a form of the text that differs or varies from its predecessor at this one point. Irrespective of the kind of change or its effect on $\boldsymbol{\omega}$, western textual critics have generally recognized all changes that impinge on a text in the course of its transmission as errors; they are errors in that they do not correctly or accurately reflect the exact wording of the original text, and therefore they are 'wrong'. The cumulative effect of these errors is seen generally as a kind of corruption of the original. It is these errors, this corruption, that the scholar through the science and art of textual criticism is expected to identify and remedy. While grounded as solidly in empirical data and objective facts as possible, still the entire enterprise is heavily judgmental and has the aura of a subjective attempt to make 'right' what is perceived as 'wrong'. In the west, the first recognition of the fact that texts inevitably become altered in the course of being copied and transmitted probably can be credited to scholars of the Alexandrian Library (third-second centuries $\mathrm{BCE}$ ) and their work to bring order to thousands of Greek manuscripts, in particular to Homeric manuscripts. ${ }^{6}$

6 Classic studies of the earliest known descriptions of what has come to be called 'textual criticism' include Sandys 1903-1908, 105-166, esp. 132-136 on Aristarchus and the Homeric texts, and Pfeiffer 1968, 210-233, esp. 215-216 on the Homeric texts. F. A. Wolf in his Prolegomena to Homer (1795) states explicitly his view that the text critical study of Homer 'began with the Alexandrian critics'. (See the English translation, Grafton et al. 1985, 111). In the 'Introduction' to his English translation of Sebastiano Timpanaro's La genesi del metodo del Lachmann, Glenn Most draws attention to the important difference between histories of classical studies such as Sandys 1903-1908 and Pfeiffer 1968, which are generally diachronic presentations on the one hand and manuals of textual criticism, which tend to be systematic, synchronic and 'cool and reasoned in tone' on the other. Timpanaro 2005, 15. It is sometime said that Cicero and other later authors (all of whose accounts seem traceable back to Cicero) claim that Peisistratus, the sixth-century BCE so-called 'tyrant of Athens', ordered the 'editing' of the manuscripts of the Iliad and the Odyssey, and that what we have now of those texts is the result of a kind of very early textual criticism. This claim, when taken at face value, is no longer given much likelihood of being correct. See Davison 1955. 
The traditional process for identifying and correcting textual errors falls typically into two stages. ${ }^{7}$ The first consists in examining and collating all extant manuscripts, and where pertinent, printed versions, of a given work in order to determine the work's earliest recoverable form. A single copy of a written text is called a witness, and the collation and sorting of the extant witnesses into hierarchical groups, a process generally called recension (often called by the pure Latin term recensio), is an effort to determine how the extant witnesses are related to one another diachronically, that is, which ones have been copied from or influenced by which other ones. The result of the collation is, ideally, a tree diagram that shows the filiation of the extant manuscripts of the work in question and allows one to infer on this basis the form of the underlying exemplar text. Such a tree diagram is called a stemma codicum, and this aspect of text study is called stemmatology. ${ }^{8}$ In the second stage, the textual critic scrutinizes the exemplar text that has been established on the basis of the recension in order to decide what words or passages should in his or her judgment be emended so as to reflect the presumed original as precisely as possible. This is usually called emendation (emendatio), sometimes called conjectural emendation or divination (divinatio) because these kinds of judgments are invariably subjective, based on the critic's 'sense' of the text's language, structure and content, rather than on any decisive objective data. ${ }^{9}$ Restorations based

7 The classic description of textual criticism as established and practiced in the study of western classical literature is Paul Maas, Textkritik, which appeared first in 1927. A second edition was published in 1949 and a third in 1957. An English translation of the second edition by Barbara Flower (d. 1955), with additional notes reflecting the third edition, was published posthumously in 1958 as Textual Criticism. Maas gives a very succinct, yet admirably precise account of the procedures and rationale of all aspects of classical textual criticism, with examples taken almost exclusively from Greek.

8 The notion of a stemma codicum arose first in early eighteenth-century New Testament exegetic studies, in particular in the work of Johann Albrecht Bengel (1687-1752) who 'imagined that [...] the whole history of the New Testament [manuscript (WGB)] tradition could be summarized in a tabula genealogica, [...], what will later come to be called a stemma codicum'. (Timpanaro 2005, 65.) Karl Lachmann (1793- 851) is often considered the scholar who established recension as a formally precise, objective and rigorous approach to the study of manuscripts, so much so that the term 'Lachmann's method' has become nearly synonymous with classical recension in general. See Timpanaro 2005.

9 More than anything else, a 'sense' of the text comes from wide reading in contemporaneous literature. The renowned Renaissance scholar Isaac Casaubon said in regard to his text critical commentary on Theophrastus's Characters: 'The authors of any period have a special quality that does not fit the writers of another period [...] it is best to explain writers by others of the same period'. See Grafton and Weinberg 2010, 17-18 and passim. This aspect of textual criticism is a major part of what A. E. Housman referred to as 'art'. While it is indeed subjective 
objectively on empirical evidence and extant data will have been proposed as a part of the first stage, that of recension.

At least four things distinguish the tradition of textual criticism in China from the traditional western practice of textual criticism, all of which have implications for how we understand the procedures and goals of textual criticism more sinico and ultimately for how we understand the relation between the producers, transmitters and consumers of early Chinese texts.

(i) First, and in some respects perhaps most important, the recognition of authorial identity and presumption of a single original text, the $\boldsymbol{\omega}$ of traditional western textual criticism, directly associated with a known author is a far more prevalent and viable presupposition in the classical west than it is in China. Authorial attributions and the presumption of textual integrity for early Chinese texts are increasingly seen to be matters of tradition more than of objective empirical fact. ${ }^{10}$ The notion of a single 'original text' identifiable with a single author may not always be the aptest way to see the putative source of the received version of a given early Chinese text. ${ }^{11}$ It seems very likely that many pre-imperial

rather than mechanically objective, it is all the same not simply imaginative guess-work. James Barr in his discussion of biblical textual criticism notes that '[i]f there is no manuscript reading to support [the critic's] conclusions, what he produces will be a conjectural emendation, which he will support by arguing that it makes much better sense. Even a conjectural emendation [...] will point out some kind of relation between the reading conjectured and the text actually found'. Barr 1987, 3. In the Preface to his recent book on textual criticism, Richard Tarrant says ' $[t]$ extual criticism deals with relative probability and persuasiveness, not with demonstration, and as a result its conclusions must always be to a degree provisional'. (Tarrant 2016, xii) This is the divinatio aspect of textual criticism. It is precisely this that Housman saw as the art of textual criticism, the subjective nature of the 'persuasiveness' of the argument and how that is a gauge of the 'probability' of the conjecture.

10 See, for example, my 'The composite nature of early Chinese texts' (Boltz 2005, 50-78).

11 The question of the 'composite' nature of authorship in pre-modern China has recently been treated at length in a collection of papers dealing with various aspects of authorship in East Asian literature. See Schwermann and Steineck 2014. Virtually all of the contributors to this work who write about China recognize the phenomenon of 'indefinite authorship' in early Chinese texts, down to as late as the early seventeenth century. Schwermann himself shows in some detail that the question of multiple authorship arises even in connection with nontransmitted texts such as bronze inscriptions (Schwermann 2014). He points out that the traditionally predominant view that inscribed bronze vessels were used exclusively for ceremonial purposes and that inscriptions were directed chiefly to the ancestors are conjectures not explicitly supported by the vessels or the inscriptions themselves. Li Feng has shown that inscribed bronze vessels could be used for such quotidian purposes as washing and food preparations (Li 
Chinese texts that have been transmitted to the present were not composed all at once as single works, each by an individual author. Many, such as the Laozi and the Zhuangzi, to name only two of the best known examples, seem, whatever the nature of their original core material, to have evolved over time through a process of accretion of individual passages, sometimes even whole chapters, from disparate, largely unidentifiable, sources. ${ }^{12}$ By the same token, the internal structure of a text might undergo rearrangement or suffer loss in the hands of readers and users of the text who for whatever reasons saw fit to revise or alter the text in which they were interested..$^{13}$ This kind of revision, known directly from recently discovered manuscripts of early texts, sometimes resulted in a 'version' of a text that differed markedly in content and structure from what would at first appear to be its received form. How such different early

Feng 2011, 271-301, esp. 293-300 and Li Feng 2018, 24-33). Some years earlier, Edward L. Shaughnessy illustrated the composite nature of an extended set of related late Western Zhou bronze inscriptions and the 'multiple author' process involved in preparing and casting them, based on evidence from three of the most important of the twenty-seven inscribed bronze vessels discovered in 2003 in Yangjiacun 楊家村 in Shaanxi province (Shaughnessy 2007). In all of these cases of bronze inscriptions the question of multiple or unknown authorship does not carry the same kind of direct implications for text critical study that it has for transmitted texts because bronze inscriptions are not transmitted texts, but we nevertheless see that the composite nature of the text and the absence of an identifiable single author are already characteristic of the earliest literary works we know.

12 The best popular example of how this aspect of a well-known text can be assessed and incorporated into a study and translation is A. C. Graham's English translation of the Inner Chapters of the Zhuangzi (Graham 1986).

13 This kind of complex manuscript situation is not unknown for western texts. The surviving Quarto and Folio witnesses of Shakespeare's King Lear 'differed in their texts in so complex a manner that a linear derivation of the Folio from the Quarto could not be posited' (Gabler 2013, 81). A stemmatic approach to determining an 'archetype-original' was unsuccessful because that method presupposes a single original and does not allow for the possibility of what is sometimes called, somewhat oxymoronically, 'multiple originals', that is, differing original versions arising from the author's own hand, and yet the evidence suggests that this is exactly what must have been the case (see Gabler 2013). And, apart from the restriction to 'multiple originals' from a single authorial hand, the King Lear situation is closely parallel to the pre-Han situation for many early Chinese texts for which we have 'multiple originals', though not necessarily from a single author's hand, or seen from the reverse perspective, the equally counterintuitive 'no originals'. The chief difference between the multiple-originals situation for King Lear and the multiple-original manuscripts situation for numerous early Chinese texts, such as the Laozi, is that no one doubts that Shakespeare wrote the text in question, and Shakespeare is a known historical figure, whereas for the Laozi and other texts with similar composite backgrounds there is no known author nor is there any reason to think that the multiple originals all came from a single hand. 
manuscript versions of the 'same' Chinese text are related to one another and to transmitted, received versions of the text in question, or how they may have arisen one from the other, often can only be explained by recognizing that the differing versions have taken shape through a compositional process that may have drawn on diverse sources, edited in varying ways at different times and assembled in different configurations from version to version. ${ }^{14}$ The differences may be extensive enough to bring into question whether what are usually regarded as two versions of the 'same' work can really be called the 'same text' or not. If one version is constituted of significantly different components, or shows a markedly different structural arrangement from another - differences that have arisen presumably as the result of alterations by different (if anonymous) compilers - are these really the same text? ${ }^{15}$

Very little, if any, of an early Chinese text's compositional vagaries are recoverable. The transmitted, received versions of pre-imperial Chinese texts that we have are typically the product of the editorial efforts of both late classical and medieval scholars, typically, but not inevitably, starting with the Han state bibliographer-archivist Liu Xiang 劉向 (77-76 BCE). ${ }^{16}$ Identifying what is the core pre-Han material in these texts and what has accrued secondarily is a highly challenging, sometimes impossible, task. It is only from the Han period on, where we know something of the context and nature of text editing, that a text's transmission can be seen to follow a trajectory roughly comparable to what is familiar from the western classical model. Given the eclectic nature of their compilation, the transmission of many pre-imperial Chinese texts does not lend itself readily to the kind of stemmatic representation or codification that can be laid out for western classical texts. The transmission of many early Chinese texts is thus said to be indeterminate, in contrast to the western classical tradition, where we can call the typical pattern of textual transmission determinate. In determinate cases textual critics know unambiguously whether the manuscripts

14 Edward L. Shaughnessy has given a good example of this point for a relatively stable text in his Rewriting Early Chinese Texts (Shaughnessy 2006), where he discusses in detail the 'Zi yi' 緇衣 ('Black Jacket') text, as transmitted in the $L i$ ji 禮記 and as known from two discovered pre-Han manuscripts, one in the Guodian corpus and one in the Shanghai Museum corpus. Shaughnessy avers that the two manuscripts are 'essentially the same text as the Li ji chapter' (Shaughnessy 2006, 64). He then proceeds to show how 'rewriting' over time has resulted in a transmitted text that differs in many places significantly in meaning and in overall thrust from the newly extant manuscripts.

15 I have tried to illustrate this point in some detail for the Laozi. See my 'Reading early Chinese manuscripts', (Boltz 2007, 477-479 and passim) and 'Why so many Laozi's?' (Boltz 2013 16 See Fölster 2016, esp. 121-127. 
that they are analyzing and collating do indeed represent the same single text associated with a known author or not and that whatever emendations they propose, however speculative they may be, are intended to be meaningfully representative of a single original. ${ }^{17}$ For classical Chinese texts this is not typically the case.

All of this means - among other things - that the oppositional and often judgmental sense of a correct reading associated with the original text of a known author $v s$. an error introduced by a later scribe or editor, known or unknown, is more sharply present in the classical western case than in China. ${ }^{18}$ Where a scholar of Greek or Latin texts can generally depend on a familiarity with and sensitivity to a known individual author's stylistic proclivities, grammatical consistency or inconsistencies, etc. as an important part of the means for detecting textual anomalies or 'error', the scholar of classical Chinese texts for his part has no such recourse and traditionally is largely unconcerned with,

17 The goal of establishing a stemma codicum for a classical (or other) western text is, to be sure, an ideal; the reality is that often the complexities of the manuscript evidence do not allow for a clear stemmatic picture. As it is traditionally conceived, the chief drawback to the stemmatological method is that it has no direct way to accommodate lateral influences of one manuscript on another, because they lie outside the diachronic lines of filiation. Mathematicians call this kind of 'vertical' filiation 'partial order'. 'A partial order establishes a relation of before and after between certain elements, but not between any two of them' (Rovelli 2018, 46-47). Recent stemmatological work, especially with Greek manuscripts, has brought considerable methodological advances to the problem of understanding and codifying the implications and consequences of lateral influences in manuscript families. In the world of Hellenic textual criticism it no longer seems as intractable a problem as it once did. See, for example, Brockmann 1992, Rashed 2001 and Tempesta 2014. I am grateful to Christian Brockmann for bringing this issue in connection with the Greek material to my attention and for providing me with these references.

18 The contrast between the western and the Chinese traditions obtains even for such cases as Virgil's Aeneid, the text of which is said to have been preserved on Virgil's death and edited by Varius Rufus on order of the emperor Augustus (see Tarrant 2016, xi-xii.). Though it cannot be known how much of the received text of the Aeneid is Virgil's original and how much comes from the editorial pen of Varius, still the text is associated with a known author and a less famous but still known editor, in tandem, which gives it its 'known author' quality, in contrast to the majority of pre-imperial Chinese texts, for which individual authors are not known and even this kind of author-editor collaborative teamwork is largely not in evidence. Dirk Meyer has given a succinct but effective discussion of the phenomenon of unknown authors and the inappropriateness of the term 'editor' as an alternative recourse to a recognized author, whether a name is known or not (Meyer 2012, 20-22). 
perhaps even unaware of, such a possibility for most of the pre-imperial, classical textual corpus. ${ }^{19}$

The consequence of this for the practice of textual criticism in the Chinese literary realm is that we must recognize that where, for example, A. E. Housman can properly talk of identifying and correcting an error in a transmitted version of Manilius's Astronomica, we can speak in the Chinese case merely of identifying and explaining the semantic import of a textual variant in, e.g. a manuscript passage that matches a part of the transmitted Laozi. We may well have no basis other than tradition for identifying one or another of the Laozi variants as 'original' or for calling one or another of them an 'error'. Housman can assume a single, original Astronomica text (in spite of some uncertainty about the author's actual name or date), and any identifiable deviations from that original he can legitimately call errors. We cannot make a comparable assumption about the Laozi, or about many other pre-imperial Chinese texts, not only because we cannot identify any historical author of the text or a single original form of the text relative to which any variation is unambiguously an error, but in many cases also because there likely never was such an individual author or single original text that can objectively be seen as the forerunner of the received text in the first place. To be sure, we may sometimes be able to determine which of two variants is likely to be the 'changed' form and which the 'source' or the 'earlier'. But 'source' or 'earlier' does not necessarily mean 'original'. Or we may be able to identify with some confidence an 'error' in a transmitted version of the text relative to an earlier edited, transmitted version of the same text or even relative to a given manuscript version, but still this is not the same thing as restoring the original.

Pre-Han and early Han manuscripts may reflect not just editorial differences among versions of the same text, but may have been created as textual adjuncts to diverse programs of doctrinal teaching, preaching, persuading or advising, sometimes to rulers of states, other times to individuals of the aristocratic class. They may have been no more than written ancillae to oral proselytizing, or perhaps they are reflective of the personal contemplative practices of an individual or private group. We have for the most part no way to know how these manuscripts

19 In his Reader on Greek textual criticism, Robert Renehan says at one point (Section 71), '[t]he reader is well advised to attend to the most minor details of style; his efforts will result in a surer and clearer command of a writer's chief stylistic distinctions' (Renahan 1969, 101). For the reader of a Classical Chinese text the comfortable assumption of a single writer with identifiable 'stylistic distinctions' that apply to the whole work is considerably less safe than it is for his Hellenist counterpart. 
were actually used. Depending on the extent to which such manuscripts differ from their source(s), they may constitute not merely different versions of a single original, but may have become genuinely, even if only partially, different texts in structure, content and purpose. Such compilations may well have seen a very limited use, both in time and place, and have been no more than a kind of ephemeral, localized textual residue of a particular doctrinal program about which, except for these written artifacts, we know nothing. It is the possibility of such wide textual latitude that gives rise to the indeterminate nature of the early lines of transmission for at least some of the pre-imperial Chinese manuscripts that we know..$^{20}$

(ii) The second thing that distinguishes the tradition of textual criticism in China from its western counterpart is the respective impact of the invention of printing in China and in the west. Scholars and students of Chinese textual criticism must ask the same question that presses urgently on western classical textual criticism, i.e., to what extent did the advent of printing and of printed editions of texts affect the nature of the works themselves, the status of variant versions and the faithful transmission of the text. ${ }^{21}$ In Europe until late in the fifteenth century, classical Greek and Latin texts (and all other texts as well) were transmitted only in manuscript form, whereas in China, by that time, classical texts had been transmitted in printed form for at least six hundred years. To be sure, the printing of fifteenth-century Europe was not the printing of ninth-century China. Chinese printing was xylographic, that is, wood-block printing, while European printing was by contrast typographic, i.e., movable type printing. The wood blocks of xylographic printing are cut from manuscript prototype models and thus retain in many respects the features of manuscripts and in some respects their inherent vulnerabilities. Wood-block printing may be thought of as a kind of 'mechanical means for manuscript replication and reproduction'. All the same, it fixes the form of a text more firmly than manuscripts proper can. Manuscript transmission generally is likelier to result in greater variation

20 This has most recently been illustrated in Martin Kern's discussion of a poem appearing in the Tsinghua manuscript Qi Ye 耆夜, which seems to be related to the Shijing ode 'Xi shuai' 蟋蟀 'Cricket' (Mao 119), (Kern 2019, 1-36, esp. 11-17). See also the discussion in Boltz 2013.

21 The question in respect to the advent of printing in Europe has been extensively dealt with, though still not exhaustively answered, by numerous scholars over several generations. Perhaps the fullest treatment is Elizabeth L. Eisenstein's major 1979 work, The Printing Press as an Agent of Change (Eisenstein 1979). Eisenstein refers to the invention of printing in Europe as a 'revolution', and to be sure, her work answers many parts of the question, but in doing so inevitably raises further points that call for attention. 
among the extant witnesses for a given text than print transmission. Manuscript copies can be highly faithful to their source, and print transmission is not immune to error and corruption, but generally speaking, printing has the salutary effect of fixing the form of a text more durably over a wider area and for a longer period of time than hand-copying does..$^{22}$ European scholars, as a consequence, confront a messier and less stable textual situation, richer in manuscripts and poorer in printed texts than do their Sinitic confrères and have come sometimes to characterize transmission and the inevitable variation to which it gives rise as a 'wholly degenerative process through which texts become 'corrupted' and "contaminated". ${ }^{23}$ In the Chinese tradition from the medieval period on (c. $1000 \mathrm{CE}$ ), textual transmission, because it involves largely printed witnesses instead of manuscripts, is likely to have given rise to less textual variation than manuscript transmission did in the west, and is therefore viewed neutrally and in some respects even benignly. What variants arose were generally regarded as little more than the expected consequence of incidental human imperfections or in the worst cases, failings. Chinese philologists recognized, of course, that errors occur, but they never raised the specter of malign forces at work on the innocent text as it makes its way, Ichabod Crane like, along its perilous route through the midnight forests of time in the way that often seems characteristic of the western attitude. ${ }^{24}$

(iii) Third is the different writing systems used in western and Chinese texts. The procedures of canonical textual criticism include the recognition of two kinds of

22 The form that is fixed by print is not necessarily the ideal or pristine original of the text in question. The easy availability of texts heavily influenced by uncritical and unsystematic conjectures of the humanists of the first half of the second millennium in comparison with those reflecting the more careful, conservative scholarship of the scriptoria often dictated the exemplars on which early European printed texts were based. As a result, what became 'fixed and durable' was often in fact not a particularly good version of the text. '[...] it was nearly always the mongrel texts produced by the activities of the humanist copyists [...] that served as printers' copy [...] the text of which represented a chance mixture of traditional readings with conjectural emendations' (Kenney 1974a, 3-4).

23 Cherniak 1994, 1-13 and passim.

24 See Cherniak 1994. The advent of printing introduces the field of bibliography as a crucial part of textual criticism. The benefits, whatever they may be, of having printed texts a half a millennium earlier in China than in Europe are balanced in a sense by the demands of bibliographic analysis and history as an integral part of textual criticism for that same five-hundred year period. The basic work on bibliography in the English textual tradition is McKerrow 1927. For the relation between bibliographical study and the textual criticism of printed works in the western (largely English) tradition, see Bowers 1964. 
textual variants, (a) lexical, where the variation reflects a difference in wording and thus in meaning (formally, even when the variation is between synonyms), and (b) (ortho)graphic, where the difference is only in how the same word is written. ${ }^{25}$ Identifying a particular instance of textual variation as either lexical or graphic in a western language text is usually straightforward and unambiguous owing to writing systems in which a single graphic element, typically a 'letter', represents the language at a level below that of the word. Words written in alphabets, abjads, abugidas or syllabaries more often than not consist of more than one graph. Single word textual variation typically consists of a difference in only one graph. Thus, the element that varies in a case of textual variation in a text written in one of these scripts is usually only a part of the written word, not the whole written form of the word(s) in question. And this makes the identification of the variant as either lexical or graphic comparatively easy. When we see $<$ CENTRE $>$, we have no trouble recognizing it as an allowable orthographic variant of < CENTER > (or vice versa), and by the same token we recognize at once that the variant pair < WHISPER > : : < WHIMPER > in D. H. Lawrence, Sons and Lovers is lexical. ${ }^{26}$ When we see $<$ COSA $>$ in a Latin text we need only a moment, or a glance at the Appendix Probi, to know that it is a 'vernacular' spelling of classical < CAUSA >, and not a different word. ${ }^{27}$

In Chinese texts by contrast, whether manuscript or printed, it is not quite this clear-cut. A single unit of the Chinese writing system, typically a 'character', represents the language fundamentally at the morphemic or lexical level. For Classical Chinese, roughly speaking, this usually means at the level of the word. And so, because Chinese characters inevitably represent words, any

25 For texts written in alphabets, abjads or abugidas, graphic variation is often said to be a variation in the shape of the graph in question and orthographic variation is a difference in spelling the same word. For Chinese language texts written in the Chinese script this is a distinction without a difference.

26 See Thorpe 1972, 54-55. Long ago, assembling notes about Marco Polo and Yuan dynasty history, I once encountered a printed reference to a paper that, apparently with vague visions of Thomas Mann in my sub-conscious, I referred to as 'Kublai Khan's Magic Mountain', only much later to be told that the correct paper title was 'Kublai Khan's Magic Fountain'.

27 Sensu stricto it is of course a different word; it is the third-century vernacular Latin word that had devolved from the Classical Latin word CAUSA. The Appendix Probi is a kind of 'prescriptive guide to correct Latin' compiled in the third or early fourth century CE. It lists 227 entries in the form ' $\mathrm{X}$, not $\mathrm{Y}$ ', where $\mathrm{Y}$ is presumably the form that was common or current at the time, regarded as 'wrong', and $\mathrm{X}$ is the preferred or 'correct' form. Thus, we find in the Appendix Probi < CAUSA NON COSA >. Among other things, this example shows that the vocalic development of Classical Latin AU to later o (cf. Sp. $\cos a$, Fr. chose) had already occurred by the time of the Appendix Probi. See Solodow 2010, 114-120. 
instance of character variation is potentially lexical variation. To be sure, it may not always be lexical variation, but unlike textual variation in alphabets, abjads and abugidas, in Chinese that possibility must always be considered at the outset. For example, is the variation X: 說 : : Y: 悅 lexical, in which case it is X: shuō 'explain' : : Y: yuè 'be pleased', or merely graphic, X: yuè 'be pleased' with Kangxi classifier 149 : : Y: yuè 'be pleased' with cl. 061 ${ }^{28}$ The graphic difference between the characters <說 > and <悅 >, i.e., between 言 and 忄 as the left-side component of the character, when both stand for the same word yue 'be pleased', can be thought of as roughly comparable to the spelling difference between English $<$ RIME $>$ and $<$ RHYME $>$ or $<$ PHANTASY $>$ and $<$ FANTASY $>$. In both the Chinese and the English cases one form is a slightly more conservative way of writing the word in question than the other. Seen in isolation, the character <說 > is completely ambiguous and cannot be read, except by arbitrarily choosing between the two possibilities shuō 'explain' and yuè 'be pleased'. This is clearly different from the English examples; nothing about the reading of $<$ RIME $>$ and $<$ RHYME $>$ or of $<$ FANTASY $>\sim<$ PHANTASY $>$ is ambiguous.

Except in a very limited way, such as graffiti, road signs, student exercise books or the like, Chinese characters do not occur in isolation, and so the problem of how to read a character in isolation generally does not arise, and when it does it will likely be marginal. But the lexical ambiguity inherent in the character <說 > is not limited to deciding how to read it in isolation. Even occurring in

28 The formulaic expression 'X: 說 : : Y: 悅' is to be understood as 'the character < 說 > in text $\mathrm{X}$ corresponding to the character <悅 $>$ in text $\mathrm{Y}$ ', where $\mathrm{X}$ and $\mathrm{Y}$ will in any actual case be identified as specific texts or parts of texts. The formula can be extended to $Z$ or to any number of matching texts that have corresponding characters. Beyond this, the convention adopted here will be to refer to the so-called 'radicals' of Chinese characters as 'classifiers' (abbr. cl.), numbered according to the traditional Kangxi zidian 康熙字典 scheme (001-214). As classifiers, these are sometimes now called taxograms. In focusing on the structural features and variation of components of traditional characters, particularly as these have evolved historically in the development of the writing system, as opposed to a concern with lexicographical classification, classifiers may also be called 'determinatives', 'significs' or 'semantic components'. Whatever term is used, they are precisely not 'radical' in any meaningful sense; they are not, in other words, the 'root' part of the character, but typically secondary or tertiary graphic additions to the core part of the character. For this reason we will avoid calling them by the term 'radical'. In the example here the word yuè 'be pleased' can be written with either <說 > or <悅 >, i.e., using either cl. 149 (言) or 061 (小, the combining form of 心), but the word shuō 'explain' is never written with cl. 061. This is not an anomalous or capricious variation, but a reflection of the fact that in at least one variety of the late Warring States period writing system(s), before the standardization in the Han period, classifiers 149, 言, suggestive of 'speech' and 061, 心, suggestive of 'mental', 'cognitive' or 'emotional' senses, were often interchangeable in characters used to write words with a noetic or emotive sense. See Park 2016, 180-182. 
a clear context, the character <說 > may be ambiguous in the same way. Look, for example, at the well-known line from book six of the Lunyu, the 'Analects' of Confucius', 子見南子, 子路不說 'The Master (= Confucius) paid a visit to Nanzi; Zi Lu (= one of Confucius's primary disciples) was not pleased'. This understanding is straightforward and based entirely on tradition. Nanzi (rendered as 'Nancy' in Lin Yutang's translation) was the wife of Commonlord Ling of the state of Wei and was reputed to have had an immoderate and uninhibited appetite for amorous recreational adventures. Confucius's visit allowed for the possibility that he partook of this delicate diversion with her, and this is what presumably provokes Zi Lu's displeasure (bú yuè 不說). ${ }^{29}$ But it is possible to understand <不說 > as bù shuō, thus making the sentence say ' $\mathrm{Zi} \mathrm{Lu} \mathrm{did} \mathrm{not}$ explain it', i.e., made no effort to account for it. Only the weight of tradition and commentarial opinion excludes this second possibility.

(iv) Finally, the fourth difference is that between a well-known and linguistically transparent inflectional morphology of most classical Indo-European and Semitic languages and the still hazy and uncertain outlines of whatever morphology the Classical Chinese language once had. Western alphabetic systems register a language's morphology explicitly, allowing for morphological, and thus grammatical, mistakes to be readily noticed. The Appendix Probi tells us, for example, < NOBISCUM NON NOSCUM > 'with us' and < VOBISCUM NON VOSCUM > 'with you (pl.)', clearly indicating the difference between a grammatically correct use of CUM 'with' with the ablative case (NOBIS, VOBIS) and a wrong use with the accusative (NOS, vos). By contrast, the Chinese writing system seems to operate free of any hint of whatever early inflectional morphology may have operated in the language, each character standing as we have said, effectively for a single word. It follows that the writing system cannot by its nature reflect the $<$ NOBISCUM NON NOSCUM > kind of difference, often referred to as 'error', that we see in western texts. Textual variants in Chinese are in principle almost always ambiguous in that by virtue of the writing system they inevitably entail the possibility of valid alternative lexical forms; variants in western language texts,

29 It is also possible that Nanzi was in fact a member of the same clan lineage as Confucius, in which case the implied dalliance would violate one of the most fundamental constraints in Chinese society, accounting for Zi Lu's displeasure in a way that goes beyond a merely conservative moral rectitude. 
written in alphabets, much less so. ${ }^{30}$ This inhibits any perception in Chinese texts that variation per se might be equal to error, still less to 'corruption'.

The first two of these four differences reflect the characteristics and physical forms of the text itself, the second two reflect the nature of the language and how it is represented in writing. In the aggregate, these four differences between the textual world of the western classics and that of the Chinese call for an understanding of the practice of textual criticism as it pertains to early Chinese texts that is markedly different from the familiar traditional practice as it is recognized in the classical west. There is a distinction in western studies between the kind of canonical textual criticism already described in some detail here, in which recension and the establishment of a reliable stemma codicum for transmitted texts are central goals, and that kind of textual criticism concerned with non-transmitted texts, as, for example, epigraphic texts or other kinds of inscriptional material. ${ }^{31}$ In the latter case there is typically minimal transmission or possibility of multiple witnesses and thus little question of establishing a stemma of any kind..$^{32}$ The text critical approach to this kind of material consists

30 Note that 'potentially valid alternatives' are judged then on the basis of meaning, at which point some of them may well be eliminated as 'not valid' because they simply do not make sense. The trick is not to decide that a variant 'does not make sense' prematurely, thereby eliminating a possibility that might in fact have merit when looked at carefully or in an expanded context.

31 A. G. Woodhead's introductory book, The Study of Greek Inscriptions, for example, does not use the term 'textual criticism' anywhere, in spite of the fact that it lays out all of the textual considerations that underpin the reading and study of these kinds of epigraphic materials. See Woodhead 1981. E. G. Turner, by contrast, in his introduction to the study of Greek papyri, uses the term 'textual criticism' to describe the exegetic study of these materials whether they are manuscripts of Greek literary works, and therefore can be fit into a textual filiation, or are nonliterary texts with no transmitted representatives. Turner points out that even though the nonliterary papyri are similar to epigraphic, inscriptional texts in being non-transmitted works, the former are likely to be far less self-consciously written than the latter, which by their nature are designed and produced for public display and consumption (Turner 1968, 127).

32 The major exception to this in the west is the large number of inscriptions that are known only from citations or quotations found in medieval manuscripts, the original epigraphic work not having survived. When a particular inscription, no longer extant, is quoted in more than one manuscript, the traditional methods of textual criticism then are required to establish the text of the inscription as accurately as possible. See Buonocore 2015, 21. In China, the situation was somewhat different. Bronze inscriptions not infrequently occur in more than one witness. The same inscription was typically cast once in the body of a bronze vessel and separately in its accompanying lid, producing two witnesses to the text. And it was common for bronzes to be cast in sets of as many as nine or more items, bell chimes for example, often with the same inscription cast in each bell, thus giving multiple witnesses to a particular text. Since each 
exclusively in determining what the author, known or unknown, intended to say in the text at hand. ${ }^{33}$ In these circumstances, what we might call the philological approach goes beyond the text critical by examining and studying the text as a historical artifact of a particular time and place, something as important for the study of Chinese bronze inscriptions as it is for western epigraphic materials. ${ }^{34}$

When this approach is extended to manuscripts, including manuscripts that may have some relation to transmitted, received texts, it re-directs the focus away from a concern with restoring a putative original to a study of the individual manuscripts themselves and their immediate contexts. This is the approach generally taken toward the study of early Chinese manuscripts. Because of the indeterminate nature of their textual history, the chief goal is to understand the early manuscripts properly seen against the historical and cultural contexts in which they occur rather than to fit them into a stemmatic scheme of transmitted literature attributed to a given author. Not only is the manuscript seen as an artifact of its own time and circumstances, but within a collection of manuscript witnesses for a given text each manuscript represents a certain point on a diachronic and areal textual trajectory. In the aggregate, the manuscripts testify to

casting was done independently of the others, the text of the inscription is amenable to text critical analysis and scrutiny in the same way that any other text is. To be sure, there is no transmission of the witnesses separately one from the other, and thus no stemmatic analysis is involved, but in other respects an early Chinese bronze inscription may well exist in multiple forms and thus call for text critical study. Beyond this, it is becoming increasingly clear that early Chinese bronze inscriptions had in fact a complex manuscript background in their production. This has been convincingly shown by Ondřej Škrabal for Western Zhou bronze inscriptions and is likely to have been the case for bronze inscriptions from later periods as well. See Škrabal 2019. This means that inscriptions can be viewed as "witnesses of their longperished drafts or [manuscript (WGB)] master-copies, perhaps not always entirely faithful ones', and this brings the 'art and science' of textual criticism into the field of epigraphy (Škrabal 2019, 275).

33 Maas 1958, 2 calls a text for which there is only a single witness a codex unicus and says that in such a case the purpose of recension consists in 'describing and deciphering as accurately as possible the single witness'.

34 For the importance of recognizing early Chinese bronze inscriptions not only as documents central to the study of early history (though sensu stricto not always primary documents), but as textual features of bronze vessels seen as physical artifacts whose full meaning can only be appreciated in conjunction with an understanding of the ceremonial use of the vessels, see von Falkenhausen 1993,146 and passim. See also Li Feng 2018, 25, pointing out that the importance and use of inscribed bronze vessels went beyond the solely religious and ceremonial and included quotidian social uses also. 
a textual fluidity that in many cases is at least as important as the traditional goal of restoring an original. This approach to manuscript study is sometimes contrasted with traditional textual criticism and called 'new philology'. ${ }^{35} \mathrm{New}$ philology does not preclude looking at questions of filiation and lines of transmission when the manuscripts provide evidence for this, it simply demotes that from center stage to one of many considerations about the individual manuscripts in question. Given the indeterminate nature of their origin, transmission and circulation history, early Chinese manuscripts readily lend themselves to the 'new philology' approach.

\section{References}

Barr, James (1987), Comparative Philology and the Text of the Old Testament, Winona Lake (Indiana): Eisenbrauns [Reprint with revisions and corrections; first edition: Oxford: Oxford University Press 1968].

Boltz, William G. (2005), 'The composite nature of early Chinese texts', in Martin Kern (ed.), Text and Ritual in Early China, Seattle: University of Washington Press, 50-78.

Boltz, William G. (2007), 'Reading early Chinese manuscripts', Journal of Chinese Studies, 47: 459-480.

Boltz, William G. (2013), 'Why so many Laozi's?', in Imre Galambos (ed.), Studies in Chinese Manuscripts: From the Warring States Period to the 20th Century, Budapest: Institute of East Asian Studies, Eötvös Loránd University, 1-31.

Bowers, Fredson (1964), Bibliography and Textual Criticism (The Lyell Lectures, 1959), Oxford: Oxford University Press.

Brockmann, Christian (1992), Die handschriftliche Überlieferung von Platons Symposion (Serta Graeca, 2), Wiesbaden: Ludwig Reichert.

Buonocore, Marco (2015), 'Epigraphic Research from its Inception: The Contribution of Manuscripts', in Christer Brunn and Jonathan Edmundson (eds), The Oxford Handbook of Roman Epigraphy, Oxford: Oxford University Press, 21-41.

Cherniak, Susan (1994), 'Book culture and textual transmission in Sung China', Harvard Journal of Asiatic Studies, 54/1: 5-125.

35 'New philology' is a kind of umbrella term for the study of manuscripts (and by extension epigraphic texts) themselves, setting aside a concern with establishing a stemma codicum and the goal of restoring an original in favor of seeing a given manuscript as a reflection of a specific context, i.e., a time, a place, a practice and all other aspects that characterize the manuscript culture from which the particular manuscript comes. See Nichols 1990 and Lied and Lundhaug 2017, 1-10. Beyond this straightforward understanding it has become in relation to the study of medieval European texts a matter of some methodological and interpretive controversy. See Kay 1999 for a succinct résumé of this aspect of the topic. 
Davison, J. A. (1955), 'Peisistratus and Homer', Transactions and Proceedings of the American Philological Association, 86: 1-21.

Eisenstein, Elizabeth L. (1979), The Printing Press as an Agent of Change: Communications and Cultural Transformations in Early-Modern Europe, New York: Cambridge University Press.

Fölster, Max Jacob (2016), The Imperial Collection of the Former Han and the Origins of Philology in China: A Study of Bielu, Qilüe and Hanshu Yiwenzhi, PhD dissertation, University of Hamburg.

Gabler, Hans Walter (2013), 'Late Twentieth-Century Shakespeares', in Neil Fraistat and Julia Flanders (eds), The Cambridge Companion to Textual Scholarship, Cambridge: Cambridge University Press, 79-96.

Grafton, Anthony (1991), Defenders of the Text. The Traditions of Scholarship in an Age of Science, 1450-1800, Cambridge, MA: Harvard University Press.

Grafton, Anthony and Joanna Weinberg (2010), 'I have always loved the Holy Tongue'. Isaac Casaubon, the Jews, and a Forgotten Chapter in Renaissance Scholarship, Cambridge, MA: Harvard University Press.

Grafton, Anthony, Glenn W. Most and James E. G. Zetzel (tr. and annotated) (1985), F. A. Wolf, Prolegomena to Homer, 1795, Princeton: Princeton University Press.

Graham, A. C. (1986), Chuang-tzu: the inner chapters, London: Unwin [often reprinted].

Greetham, D. C. (1994), Textual Scholarship, an Introduction, New York: Garland.

Housman, A. E. (1922), 'The application of thought to textual criticism', Proceedings of the Classical Association, 18: 67-84 [reprinted in A. E. Housman, The Name and Nature of Poetry and Other Selected Prose, ed. by John Carter, Cambridge: Cambridge University Press, 1961, 131-150.

Kay, Sarah (1999), 'Analytical survey 3: The New Philology', in David Lawton, Wendy Scase and Rita Copeland (eds), New Medieval Literatures, Oxford: Oxford University Press, 295-326.

Kenney, E. J. (1974a), The Classical Text, Berkeley: University of California Press.

Kenney, E. J. (1974b), 'Textual Criticism', in Encyclopaedia Britannica, 15th edn, online edition. Kern, Martin (2019), “Xi shuai” 蟋蟀 [“cricket”] and its Consequences: Issues in Early Chinese Poetry and Textual Studies', Early China 42: 39-74 <https://doi-org.offcampus.lib. washington.edu/10.1017/eac.2019.1>.

Li Feng (2011), 'Literacy and the Social Contexts of Writing in the Western Zhou', in Li Feng and David Prager Branner (eds), Writing and Literacy in Early China: Studies from the Columbia Early China Seminar, Seattle, WA: University of Washington Press, 271-301.

Li Feng (2018), 'The Development of Literacy in Early China: With the Nature and Uses of Bronze Inscriptions in Context, and More', in Anne Kolb (ed.), Literacy in Ancient Everyday Life, Berlin: De Gruyter, 13-42.

Lied, Liv Ingeborg and Hugo Lundhaug (2017), Snapshots of Evolving Traditions: Jewish and Christian Manuscript Culture, Textual Fluidity, and New Philology (Texte und Untersuchungen zur Geschichte der altchristlichen Literatur, 175), Berlin: De Gruyter.

Maas, Paul (1958), Textual Criticism, tr. from German by Barbara Flower, Oxford: Clarendon [translation of Paul Maas, Textkritik, 3rd revised and enlarged edn, Leipzig: Teubner, 1957].

McKerrow, Ronald B. (1927), An Introduction to Bibliography, Oxford: Oxford University Press [often reprinted].

Meyer, Dirk (2012), Philosophy on Bamboo: Text and the Production of Meaning in Early China. Leiden: Brill. 
Nichols, Stephen G. (1990), 'Introduction: Philology in a Manuscript Culture', Speculum, 65/1: 1-10.

Park, Haeree (2016), The Writing System of Scribe Zhou, Berlin: De Gruyter.

Pfeiffer, Rudolf (1968), History of Classical Scholarship, Oxford: Oxford University Press.

Rashed, Marwan (2001), Die Überlieferungsgeschichte der aristotelischen Schrift De generatione et corruptione (Serta Graeca, 12), Wiesbaden: Ludwig Reichert.

Renahan, Robert (1969), Greek Textual Criticism: A Reader, Cambridge, MA: Harvard University Press.

Reynolds, L. D. and N. G. Wilson (1991), Scribes and Scholars: A Guide to the Transmission of Greek and Latin Literature, 3rd edn, Oxford: Oxford University Press [1st edn: 1968].

Rovelli, Carlo (2018), The Order of Time, New York: Riverhead.

Sandys, John Edwin (1903-1908), A History of Classical Scholarship, Cambridge: Cambridge University Press.

Schwermann, Christian (2014), 'Composite Authorship in Western Zhōu Bronze Inscriptions, the Case of the “Tiān wáng gǔi” 天王笽 Inscription', in Schwermann and Steineck (eds) 2014, 30-57.

Schwermann, Christian and Raji C. Steineck (eds) (2014), That Wonderful Composite Called Author, Leiden: Brill.

Shaughnessy, Edward L. (2006), Rewriting Early Chinese Texts, Albany, NY: State University of New York.

Shaughnessy, Edward L. (2007), 'The Writing of a Late Western Zhou Bronze Inscription', Asiatische Studien / Études asiatiques, 61/3: 845-877.

Škrabal, Ondřej 2019, 'Writing before Inscribing: On the Use of Manuscripts in the Production of Western Zhou Bronze Inscriptions', Early China, 42: 273-332 <doi:10.1017/eac.2019.9〉.

Solodow, Joseph B. (2010), Latin Alive, Cambridge: Cambridge University Press.

Tarrant, Richard (2016), Texts, Editors, and Readers: Methods and Problems in Latin Textual Criticism, Cambridge: Cambridge University Press.

Tempesta, Stefano Martinelli (2014), 'Missing “Archetype”: The Transmission of the Isocratean Corpus and the Problems of the constitutio textus', in Christian Brockmann, Daniel Deckers, Lutz Koch and Stefano Valente (eds), Handschriften- und Textforschung heute (Serta Graeca, 30), Wiesbaden: Ludwig Reichert, 43-54.

Thorpe, James (1972), Principles of Textual Criticism, San Marino, CA: The Huntington Library. Timpanaro, Sebastiano (2005), The Genesis of Lachmann's Method, edited and translated by Glenn W. Most, Chicago: University of Chicago Press.

Turner, E. G. (1968), Greek Papyri, an Introduction, Oxford: Clarendon.

von Falkenhausen, Lothar (1993), 'Issues in Western Zhou Studies', Early China, 18: 139-226.

Walsh, Marcus (2013), 'Theories of Text, Editorial Theory, and Textual Criticism', in Michael F. Suarez and H. R. Woudhuysen (eds), The Book, A Global History, Oxford: Oxford University Press, 258-270 (Chapter 20).

Woodhead, A.G. (1981), The Study of Greek Inscriptions, 2nd edn, Cambridge: Cambridge University Press. 
